\title{
Fontes e doses de boro em porta-enxertos de seringueira
}

\author{
Adônis Moreira $^{(1)}$, Vicente Haroldo de Figueiredo Moraes $^{(2)}$ e César de Castro ${ }^{(3)}$
}

\begin{abstract}
(1)Embrapa Pecuária Sudeste, Caixa Postal 339, CEP 13560-970 São Carlos, SP. E-mail: adonis@cppse.embrapa.br (2)Embrapa Amazônia Ocidental, Caixa Postal 319, CEP 69011-970 Manaus, AM. E-mail: vicente@cpaa.embrapa.br (3)Embrapa Soja, Caixa Postal 231, CEP 86001-970 Londrina, PR. E-mail: ccastro@cnpso.embrapa.br
\end{abstract}

Resumo - Este trabalho teve por objetivo avaliar o efeito da aplicação de boro sobre o incremento do diâmetro do caule no ponto de enxertia, $5 \mathrm{~cm}$ acima do coleto, número e diâmetro de raízes laterais e estado nutricional de porta-enxertos para produção de toco enxertado de raiz nua. O delineamento experimental foi o de blocos ao acaso, em esquema fatorial 2x5: duas fontes (ulexita, 10\% de B e ácido bórico, 17\% de B) e cinco doses de B $\left(0,2,4,8\right.$ e $\left.16 \mathrm{~kg} \mathrm{ha}^{-1}\right)$ com quatro repetições. Em condições edafoclimáticas locais, curvas de resposta indicam aumentos significativos, no incremento do diâmetro do caule, no ponto de enxertia, nas doses 6,5 e $16 \mathrm{~kg} \mathrm{ha}^{-1} \mathrm{de} \mathrm{B}$, e no número de raízes laterais, nas doses 13,9 e $16 \mathrm{~kg} \mathrm{ha}^{-1}$ de B, com aplicação de ácido bórico e de ulexita, respectivamente. As doses de $\mathrm{B}$ não afetaram o número de raízes. O nível crítico de $\mathrm{B}$ na folha de mudas de seringueira, alcançado com aplicação de ácido bórico, é de 31,8 $\mathrm{mg} \mathrm{kg}^{-1}$. As doses de B apresentam interações significativas com os teores foliares de B, Mn e Zn, enquanto os teores foliares de N, P, K, Ca, Mg, S, Na, Cu e Fe não variaram significativamente em razão das doses de B.

Termos para indexação: Hevea brasiliensis, concentração de nutrientes, diâmetro do caule, ulexita, ácido bórico.

\section{Sources and rates of boron in rubber rootstocks}

\begin{abstract}
The objective of this work was to evaluate the effect of boron supply on the increment of stem diameter, number and diameter of lateral roots and the nutritional status of rubber rootstocks at the budding height ( $5 \mathrm{~cm}$ above the root collar), for the production of base root budded stumps, in a Xanthic Ferralsol. The experimental design was in randomized blocks, in a 2x5 factorial scheme: two sources (ulexite $-10 \%$ of $\mathrm{B}$ and boric acid $-17 \%$ of B) and five B rates (0, 2, 4, 8 and $\left.16 \mathrm{~kg} \mathrm{ha}^{-1}\right)$, with four replicates. Under the local conditions, the response curves showed significant increases in increment of stem diameter at 6.5 and $16 \mathrm{~kg} \mathrm{ha}^{-1} \mathrm{~B}$, and in the number of lateral roots at 13.9 and $16 \mathrm{~kg} \mathrm{ha}^{-1} \mathrm{~B}$, with boric acid and ulexite, respectively. The $\mathrm{B}$ rate did not improve the number of lateral of roots. The critical level of boron in leaf of rubber rootstocks obtained with boric acid is $31.8 \mathrm{mg} \mathrm{kg}^{-1}$. The $\mathrm{B}$ rates supply presented significant interactions with the leaf contents of $\mathrm{B}, \mathrm{Mn}$ and $\mathrm{Zn}$, while leaf contents of N, P, K, Ca, Mg, S, Na, Cu and Fe did not vary in function of B rates.
\end{abstract}

Index terms: Hevea brasiliensis, concentration of nutrients, stem diameter, ulexite, boric acid.

\section{Introdução}

A seringueira é propagada comercialmente por mudas enxertadas. Essas mudas são obtidas de porta-enxertos provenientes de sementes ilegítimas, colhidas em seringais de cultivo, e plantadas em sementeiras para seleção das mudas, e posterior plantio em viveiro.

Experimentos conduzidos em Belém, PA, e em Manaus, AM, demonstraram viabilidade técnica e econômica do plantio de viveiro de seringueira em espaçamento adensado, com densidade inicial de 95 mil plantas por hectare, cujo aproveitamento é reduzido de 50 a $60 \%$, depois do desbaste das plantas que não atingiram o tamanho mínimo para a enxertia, ou com defeito da raiz pivotante. Os porta-enxertos selecionados para a enxertia devem ter diâmetro mínimo do caule de $2 \mathrm{~cm}$, a $5 \mathrm{~cm}$ do solo (Pereira \& Pereira, 1986).

Existe consenso de que a principal função do B está relacionada às estruturas primárias da parede celular, mais especificamente na síntese de pectina, celulose e lignina (Power \& Woods, 1997; Moraes et al., 2002). A carência de B resulta em rápida inibição no crescimento das plantas (Hu \& Brown, 1997). 
Na seringueira, Moraes et al. (2002) observaram, em plantio comercial com três anos, que a carência de B causou encurvamento do caule; essa anomalia é conseqüência da pouca coesão entre os elementos do lenho, causada pela redução dos constituintes da lamela média, principalmente dos pectatos de cálcio, cuja síntese é bloqueada pela carência do nutriente.

A carência de B causa inibição da elongação das raízes, devido a problemas observados durante a divisão celular e na elongação das células, tornando-as grossas e com as pontas necróticas (Loué, 1993; Marschner, 1995). Sua deficiência também afeta a complexação de compostos orgânicos da função cis-diol, inibindo o crescimento das raízes. O envolvimento do B no metabolismo de fenóis e do ácido indolacético (AIA) também pode causar a morte dos pontos de crescimentos e necrose em folhas novas (Römheld, 2001).

Nas plantas, a translocação do B ocorre preferencialmente via xilema e, para o suprimento contínuo aos ápices caulinares em crescimento, a aplicação no solo é o método que se mostrou mais eficiente. As doses de $\mathrm{B}$ empregadas na adubação situam-se entre 0,5 e 2 kg ha-1. Em solos de textura média a argilosa, fontes solúveis mostram-se mais eficientes. O contrário ocorre em solos arenosos, em que fontes de baixa solubilidade têm se mostrado superiores (Martens \& Westermann, 1991).

O objetivo deste trabalho foi avaliar o efeito da aplicação de B com diferentes fontes sobre o incremento do diâmetro do caule no ponto de enxertia, números e diâmetro de raízes laterais e estado nutricional de portaenxertos para produção de toco enxertado de raiz nua, cultivadas em Latossolo Amarelo distrófico, textura argilosa.

\section{Material e Métodos}

O experimento foi conduzido em condições de campo, de 16/4 a 21/10/2001, em Latossolo Amarelo distrófico, textura argilosa, localizado no campo experimental da Embrapa Amazônia Ocidental, a 3ㅇ's e 59²5'W, no Município de Manaus, Estado do Amazonas (Tabela 1).

O clima da região é o tropical úmido, tipo Afi, pela classificação de Köppen, com chuvas relativamente abundantes durante todo o ano (média de $2.250 \mathrm{~mm}$ ), e a quantidade, no mês de menor precipitação, é sempre superior a $60 \mathrm{~mm}$. A temperatura média na região é de aproximadamente $26^{\circ} \mathrm{C}$ (Vieira \& Santos, 1987).
Em um viveiro de 60x15 m, os porta-enxertos, obtidos de sementes ilegítimas do clone Fx 25 (Hevea brasiliensis), foram dispostos em blocos de seis linhas espaçadas de 1,2 m.

No preparo da área, três meses antes da repicagem das sementes pré-germinadas, foram aplicados, antes da aração, 90 kg de calcário dolomítico com 26,37\% de $\mathrm{CaO}, 12,42 \%$ de $\mathrm{MgO}$ e PRNT = 77,99 e, dois meses depois, foram colocados em cobertura $9 \mathrm{~kg}$ de superfosfato triplo (100 kg ha-1), seguindo-se o destorroamento do solo com enxada rotativa. Antes da repicagem das sementes, foram feitas aplicações dos fertilizantes de acordo com recomendações adaptadas de Pereira \& Pereira (1986); em sulcos rasos, foram colocados $60 \mathrm{~g}$ por metro linear da mistura contendo $100 \mathrm{~kg}$ de superfosfato triplo $\left(41 \mathrm{~kg}\right.$ de $\left.\mathrm{P}_{2} \mathrm{O}_{5}\right)+10 \mathrm{~kg}$ de $\mathrm{CuSO}_{4}(12,67 \mathrm{~kg}$ de $\mathrm{Cu})+10 \mathrm{~kg}$ de $\mathrm{ZnSO}_{4}(13,94 \mathrm{~kg}$ de $\mathrm{Zn}$ ), equivalente a $696,9 \mathrm{~kg} \mathrm{ha}^{-1}$ de superfosfato triplo, 97,5 kg ha-1 de $\mathrm{CuSO}_{4}$ e 69,7 kg ha-1 de $\mathrm{ZnSO}_{4}$. Em cobertura, foram aplicados 62,72 kg de uréia (314 kg ha-1 de N), 41,80 kg de sulfato de amônio (93 kg ha-1 de N) e 62,65 $\mathrm{kg}$ de cloreto de potássio (418 $\mathrm{kg} \mathrm{ha}^{-1} \mathrm{de} \mathrm{K}_{2} \mathrm{O}$ ), fracionados em seis aplicações mensais a partir do 2 oㅡês depois do plantio.

Dois meses depois do plantio foi realizado, antes da aplicação dos tratamentos, o primeiro desbaste, com

Tabela 1. Características químicas do solo antes da aplicação dos tratamentos e depois das coletas dos dados nas profundidades de 0-20 e 20-40 cm. Média de todos os tratamentos.

\begin{tabular}{|c|c|c|c|c|}
\hline \multirow[t]{3}{*}{ Características químicas } & \multicolumn{4}{|c|}{ Profundidades $(\mathrm{cm})$} \\
\hline & \multicolumn{2}{|c|}{$0-20$} & \multicolumn{2}{|c|}{$20-40$} \\
\hline & Antes & Depois & Antes & Depois \\
\hline$\overline{\mathrm{pH}}\left(\mathrm{CaCl}_{2} 0,01 \mathrm{~mol} \mathrm{~L}^{-1}\right)$ & 4,5 & 3,5 & 4,1 & 3,6 \\
\hline Matéria orgânica $\left(\mathrm{g} \mathrm{kg}^{-1}\right)^{(1)}$ & 38,9 & 26,4 & 26,6 & 21,9 \\
\hline$P\left(\mathrm{mg} \mathrm{dm}^{-3}\right)^{(2)}$ & 14,2 & 47,0 & 13,0 & 32,1 \\
\hline $\mathrm{K}\left(\mathrm{mg} \mathrm{dm}^{-3}\right)^{(2)}$ & 31,4 & 66,6 & 19,6 & 62,7 \\
\hline $\mathrm{Ca}\left(\mathrm{cmol}_{\mathrm{c}} \mathrm{dm}^{-3}\right)^{(3)}$ & 0,5 & 0,1 & 0,2 & 0,1 \\
\hline $\left.\mathrm{dm}^{-3}\right)^{(3)}$ & 0,2 & 0,1 & 0,1 & 0,1 \\
\hline $\mathrm{Al}\left(\mathrm{cmol}_{\mathrm{c}} \mathrm{dm}^{-3}\right)^{(3)}$ & 0,6 & 2,0 & 0,9 & 1,8 \\
\hline $\mathrm{H}+\mathrm{Al}\left(\mathrm{cmol}_{\mathrm{c}} \mathrm{dm}^{-3}\right)^{(4)}$ & 6,0 & 9,16 & 7,1 & 8,1 \\
\hline $\begin{array}{l}\mathrm{B}\left(\mathrm{mg} \mathrm{dm} \mathrm{dm}^{-3}\right)^{(5)} \text { - ácido } \\
\text { bórico }\end{array}$ & 0,14 & 0,48 & 0,12 & 0,46 \\
\hline $\left.\mathrm{B}(\mathrm{mg} \mathrm{dm})^{-3}\right)^{(5)}-$ ulexita & 0,14 & 0,58 & 0,12 & 0,39 \\
\hline $\left.\mathrm{n}^{-3}\right)^{(2)}$ & 2,4 & 5,0 & 1,5 & 3,8 \\
\hline $\mathrm{Fe}\left(\mathrm{mg} \mathrm{dm}^{-3}\right)^{(2)}$ & 367,9 & 178,1 & 482,2 & 104,2 \\
\hline $\operatorname{Mn}\left(\mathrm{mg} \mathrm{dm}^{-3}\right)^{(2)}$ & 5,2 & 3,7 & 3,5 & 2,3 \\
\hline $\mathrm{Zn}\left(\mathrm{mg} \mathrm{dm}^{-3}\right)^{(2)}$ & 3,0 & 4,9 & 2,4 & 3,5 \\
\hline Argila $\left(\mathrm{g} \mathrm{kg}^{-1}\right)$ & 719,50 & & 763,71 & \\
\hline
\end{tabular}

${ }^{(1)}$ Método Walkley \& Black. (2)Extrator Mehlich 1. (3)Extrator KCI $1,0 \mathrm{~mol} \mathrm{~L}^{-1}$. (4) Extrator $\mathrm{Ca}\left(\mathrm{CH}_{3} \mathrm{COO}\right)_{2} \cdot \mathrm{H}_{2} \mathrm{O} \quad 0,5 \mathrm{~mol} \mathrm{~L}^{-1}$. ${ }^{(5)}$ Extrator água quente, dose $16 \mathrm{~kg} \mathrm{ha}^{-1} \mathrm{de} \mathrm{B}$. 
eliminação das plantas fracas (em torno de 32\%) e, posteriormente, um segundo, no décimo mês. Foram deixados somente os porta-enxertos mais vigorosos, com diâmetros superiores a $1,5 \mathrm{~cm}$ no local de enxertia $(5 \mathrm{~cm}$ acima do coleto da planta).

O delineamento experimental foi o de blocos ao acaso, em esquema fatorial $2 \times 5$ : foram estudadas duas fontes (ulexita - 10\% de B e ácido bórico - 17\% de B) e cinco doses de B (0, 2, 4, 8 e $\left.16 \mathrm{~kg} \mathrm{ha}^{-1}\right)$ foram aplicadas a lanço, ao redor das mudas, com quatro repetições. Cada parcela foi constituída por seis fileiras de $5 \mathrm{~m}$, com espaçamento de $0,6 \mathrm{~m}$ entre elas, contendo em média 100 plantas. Em cada tratamento, foram analisadas 20 plantas, ao acaso, localizadas nas quatro fileiras centrais.

Dois meses depois do plantio, juntamente com a aplicação dos tratamentos, foi realizada a primeira medição do diâmetro do caule no ponto de enxertia (5 cm acima do coleto da planta) e, 189 dias depois da primeira leitura, foi realizada, na mesma planta, a segunda medição do diâmetro. Por meio desses resultados, foi determinado o acréscimo, pela diferença entre a segunda medida, obtida no final, e a primeira, do início do experimento. Para análise foliar, na ocasião da última avaliação do diâmetro, foram coletadas amostras compostas de folhas recém-maduras do terço médio (Shorrocks, 1961) das 20 plantas pertencentes a cada parcela útil do experimento.

As folhas foram lavadas em água corrente e, enxaguadas em água destilada. Posteriormente, foram submetidas à secagem em estufa de aeração forçada a $65^{\circ} \mathrm{C}$, moídas, e digeridas para obtenção dos extratos nítrico-perclórico (P, K, Ca, Mg, Na, S, Cu, Fe, Mn e $\mathrm{Zn})$ e sulfúrico (N). Os teores de $\mathrm{P}$ foram determinados pelo método da colorimetria do metavanadato, e os de $\mathrm{K}$ e Na, por fotometria de chama; os de $\mathrm{Ca}, \mathrm{Mg}, \mathrm{Cu}, \mathrm{Fe}$, Mn e Zn, por espectrometria de absorção atômica, e os de $\mathrm{S}$, por turbidimetria do $\mathrm{BaSO}_{4}$. O N foi quantificado pelo método semimicro Kjeldahl e determinado por titulação, enquanto o B foi extraído por meio da incineração a $550^{\circ} \mathrm{C}$ e determinado por colorimetria de azometina H (Malavolta et al., 1997).

No final do experimento, seis plantas úteis foram arrancadas de cada parcela, com remoção lateral do solo, sem ferir as raízes nas proximidades da pivotante; em seguida contou-se o número de raízes laterais com diâmetro acima de $1,5 \mathrm{~mm}$ até $20 \mathrm{~cm}$ abaixo do coleto e mediu-se o diâmetro das oito raízes mais próximas do coleto, com diâmetro a partir de 1,5 mm.
O B disponível do solo foi determinado em água quente, e a leitura foi realizada por espectrofotometria, usando o reagente colorimétrico Azometina $\mathrm{H}$ (Abreu et al., 2001), no comprimento de onda de $420 \mathrm{~nm}$. Os demais atributos do solo (pH, MO, P, Na, Ca, Mg, $\mathrm{H}+\mathrm{Al}, \mathrm{Al}, \mathrm{Cu}, \mathrm{Fe}, \mathrm{Mn}, \mathrm{Zn}$ e argila) foram analisados conforme métodos descritos pela Embrapa (1997).

Na comparação das fontes, foi determinado o índice de eficiência agronômica das fontes de B (IEB), e os valores foram expressos pela seguinte equação, adaptada de Peruzzo et al. (1994):

IEB(\%) = 100[(PMEU - PTEU)/(PMEH - PTEH)], em que PMEU é a produção máxima estimada pela equação ulexita; PTEU é a produção da testemunha estimada pela equação ulexita; PMEH é a produção máxima pela equação ácido bórico; PTEU é a produção da testemunha estimada pela equação ácido bórico.

De acordo com o delineamento proposto, o incremento do diâmetro do caule, no ponto de enxertia, o número e o diâmetro de raízes laterais, além do estado nutricional, foram submetidos à análise de variância, teste F, regressões, correlações e teste de Tukey, a 5\% de probabilidade, conforme métodos descritos por Pimentel-Gomes \& Garcia (2002).

\section{Resultados e Discussão}

Houve interação significativa das doses de B com as fontes, no crescimento do diâmetro do caule até o ponto de enxertia, e com o número de raízes laterais até $20 \mathrm{~cm}$ de profundidade. Esse fato não foi observado no diâmetro médio das raízes mais próximas ao coleto (Figura 1). Com relação às fontes, foi verificada resposta significativa e linear à aplicação de B com ulexita, enquanto na forma de ácido bórico, o efeito foi quadrático, havendo, neste caso, aumento do diâmetro do caule e do número de raízes laterais até as doses estimadas de 6,5 e 13,9 kg ha-1 de $\mathrm{B}$, respectivamente (Figura 1).

O efeito linear positivo das doses de ulexita, aliado à baixa movimentação do B para as camadas mais profundas com aplicação dessa fonte, asseguraram a disponibilidade do nutriente em níveis adequados, durante o desenvolvimento dos porta-enxertos, sem causar problemas de fitotoxidez, até a dose $16 \mathrm{~kg} \mathrm{ha}^{-1}$. O ácido bórico apresenta alta solubilidade em água e está presente no solo na forma molecular e não iônica, o que favorece seu caminhamento em profundidade (Tabela 1) e possibilita um maior contato com o sistema radicular das plantas. 
Além da solubilidade distinta das fontes de B utilizadas, outros fatores inerentes aos solos da região, como altos teores de $\mathrm{Fe}$, Al e argila (Tabela 1), devem ter interferido na disponibilidade desse nutriente, com

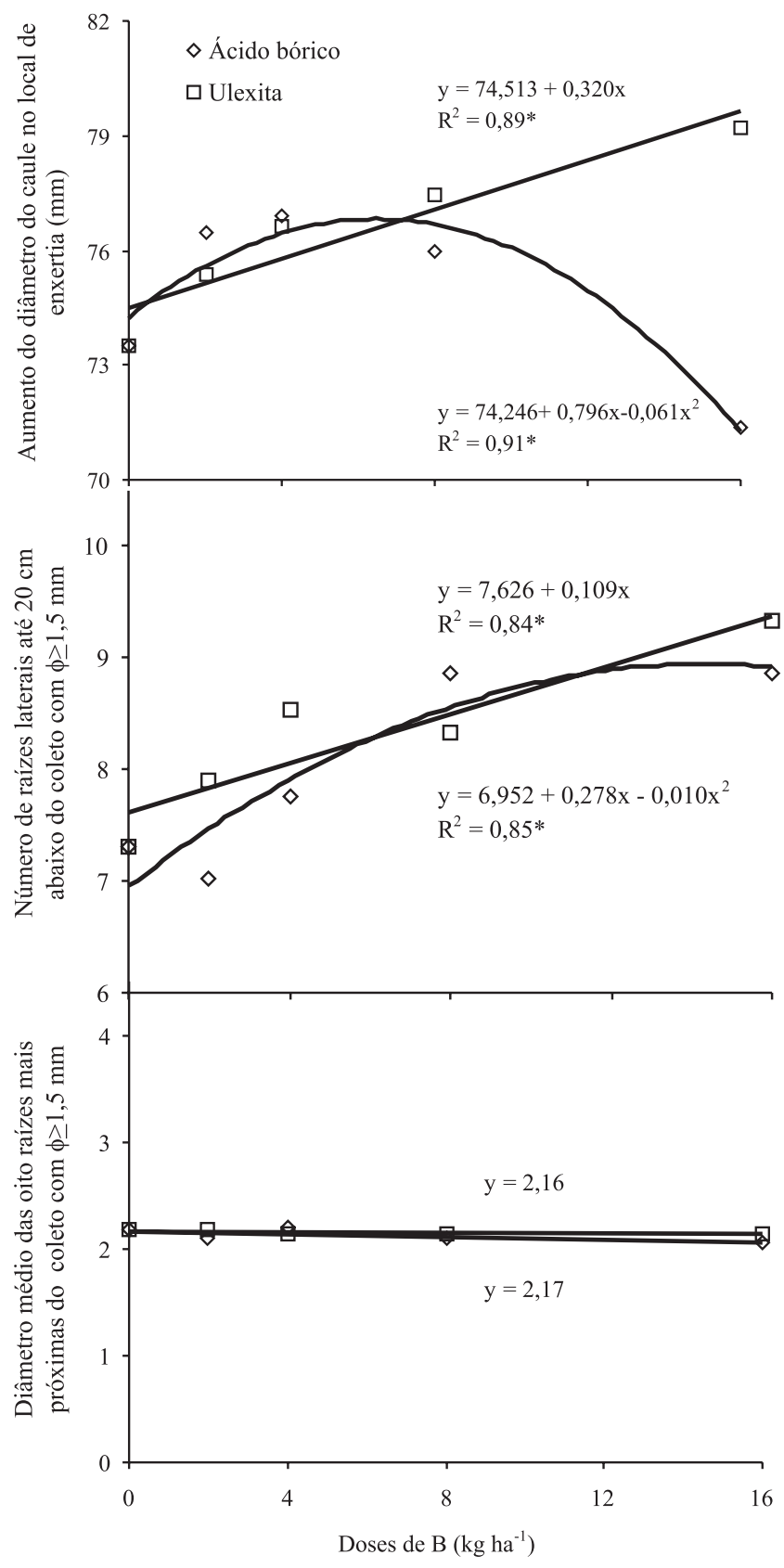

Figura 1. Aumento do diâmetro do caule de mudas de seringueira na altura de enxertia, número de raízes laterais, localizadas a $20 \mathrm{~cm}$ abaixo do coleto, e diâmetro médio de oito raízes laterais próximas ao coleto, em razão das doses de boro em diferentes fontes. *Significativo a 5\% de probabílidade pelo teste F. efeito sobre o desenvolvimento das plantas (Magalhães \& Monnerat, 1978). Blevins (1987) observou que, devido à similaridade estrutural, os sintomas iniciais de deficiência de $\mathrm{B}$ e toxidez de $\mathrm{Al}$ são parecidos, e muitos desses sintomas estão associados à função da membrana celular e ao crescimento radicular. Lenoble et al. (1996) verificaram que, em solo com alto teor de $\mathrm{Al}$, a adubação com B acarreta em aumento significativo no volume de raízes.

A correlação significativa entre o incremento do diâmetro do caule, no ponto de enxertia, e o número de raízes laterais, verificada pela equação y $=487,43$ $12,86 \mathrm{x}+0,09 \mathrm{x}^{2}(\mathrm{r}=0,61, \mathrm{p}<0,05)$, corrobora os resultados de Nascimento Filho et al. (1993), em estudos com guaranazeiro cultivado nas mesmas condições edafoclimáticas. A carência de B reduz o volume explorado pelo sistema radicular (Loué, 1993) e, conseqüentemente, a disponibilidade de água e dos demais nutrientes, o que afeta de forma direta o desenvolvimento das plantas.

Para obtenção do maior crescimento do diâmetro do caule e do número de raízes, verificou-se que a aplicação de $16 \mathrm{~kg} \mathrm{ha}^{-1}$ de $\mathrm{B}$, na forma de ulexita, mostrou-se mais eficiente, apresentando IEB 197 e $78 \%$, respectivamente, superiores às melhores doses estimadas de B com o ácido bórico como fonte (Tabela1).

Os teores foliares de B aumentaram linearmente em função das doses, com ambas as fontes, havendo correlação significativa entre o B na folha e o disponível no solo (Figura 2). Os teores foliares variaram de $25,84 \mathrm{mg} \mathrm{kg}^{-1}$, na testemunha do tratamento com ácido bórico, a 46,48 $\mathrm{mg} \mathrm{kg}^{-1}$, na dose $16 \mathrm{~kg} \mathrm{ha}^{-1} \mathrm{de}$ $\mathrm{B}$, na forma de ulexita.

Somente a partir da dose $8 \mathrm{~kg} \mathrm{ha}^{-1}$ de B, os teores foliares ficaram próximos de 40,6 e $44 \mathrm{mg} \mathrm{kg}^{-1}$, valores considerados adequados por Bolle-Jones (1954), para mudas de seringueira e por Zhonggen (1981), em planta adulta. Contudo, ficaram abaixo dos teores ditos médios de $58 \mathrm{mg} \mathrm{kg}^{-1}$ de B, obtidos por Viégas et al. (1992), em mudas cultivadas em condições de viveiro até 240 dias.

Para as condições edafoclimáticas locais, foi calculado, por meio do incremento do diâmetro do caule, o nível crítico de B nas folhas, obtendo-se o valor de $31,8 \mathrm{mg} \mathrm{kg}^{-1}$ para folhas recém-maduras, 

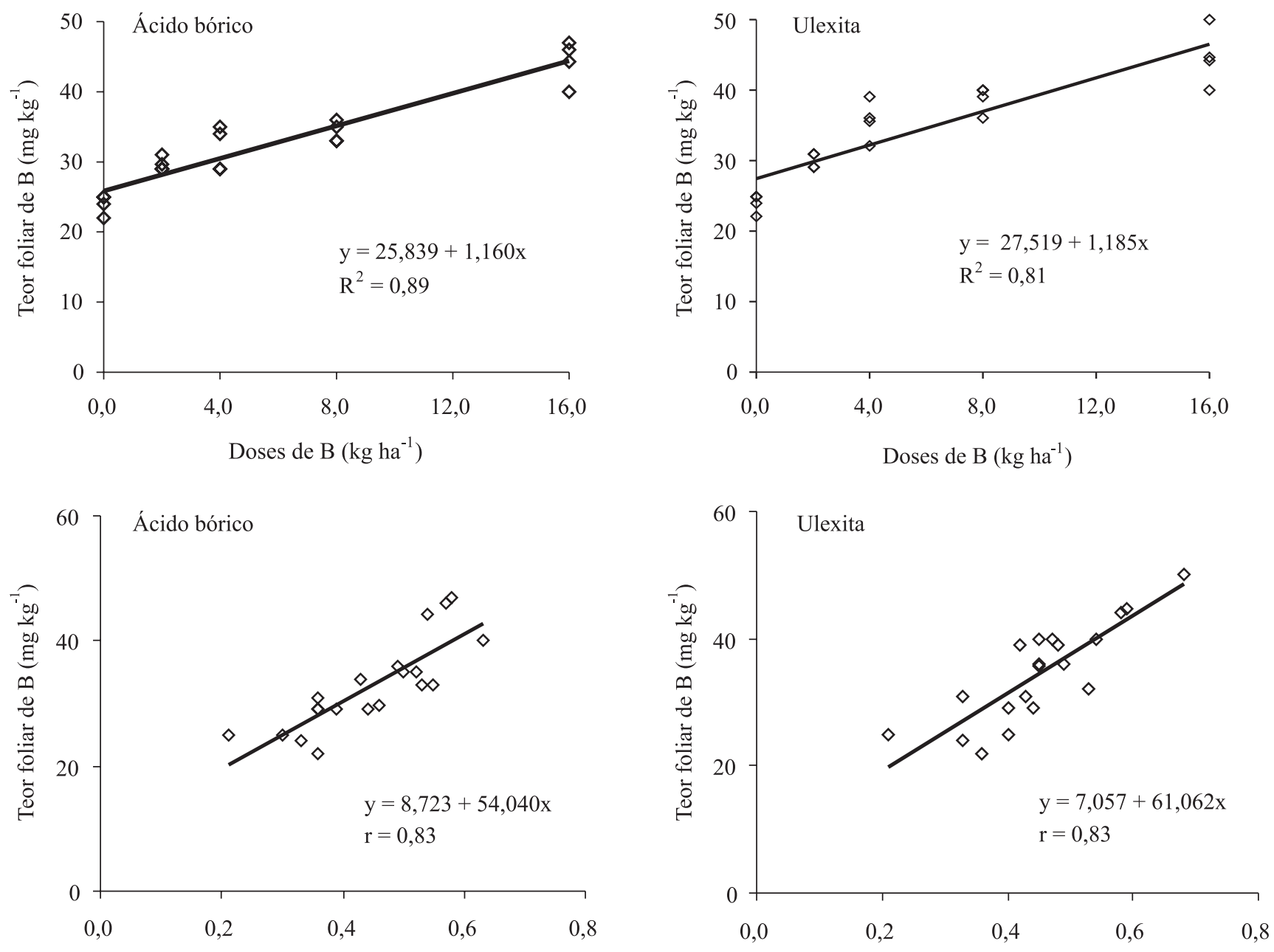

Boro disponível no solo $\left(\mathrm{mg} \mathrm{kg}^{-1}\right)$
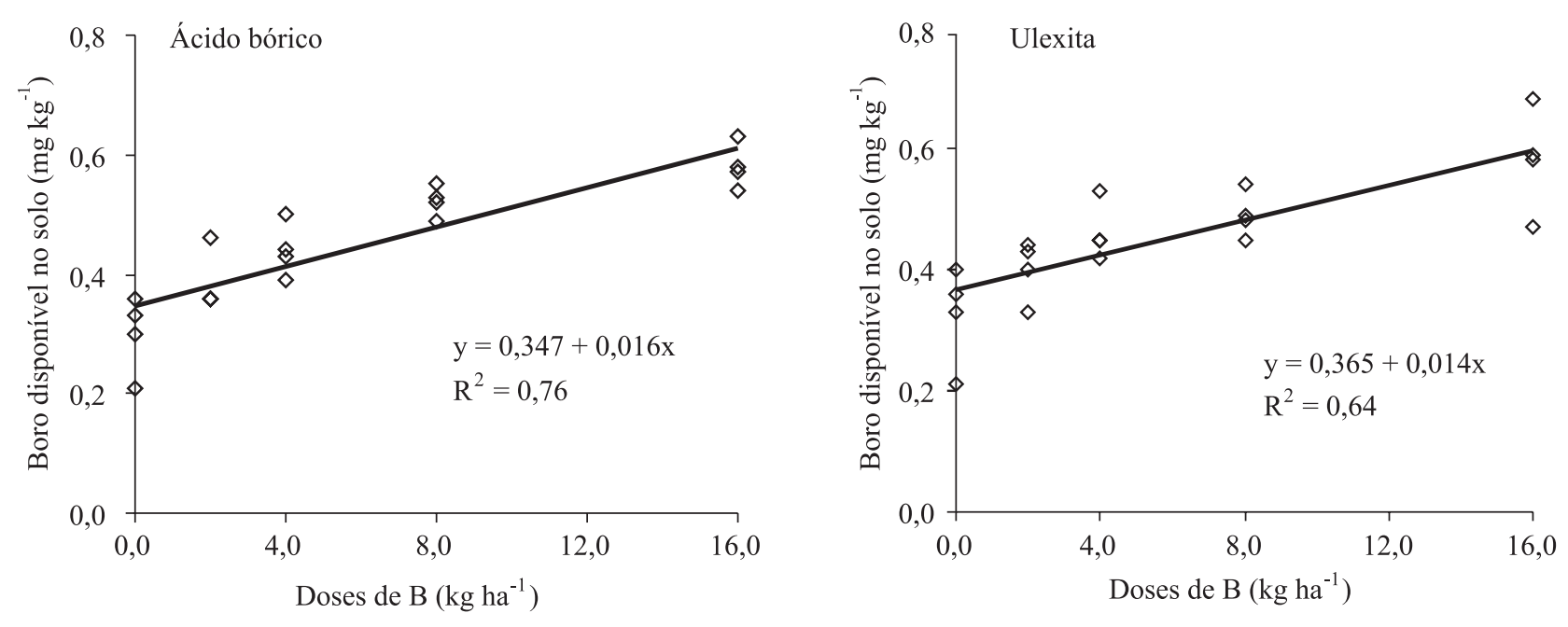

Figura 2. Equações de regressão entre o teor foliar de B e o teor de B disponível no solo, em diferentes doses de B aplicadas no solo, e correlações entre o teor foliar e o teor de B disponível no solo. 
localizadas no terço médio superior de mudas de portaenxerto de seringueira (Figura 3). Devido ao efeito linear positivo obtido com a ulexita, não foi possível traçar o nível crítico para essa fonte (Figuras 1 e 2).

Apesar do efeito negativo de elevadas doses de ácido bórico no incremento do diâmetro e no número de raízes, não foram observados sintomas visuais de deficiência ou toxicidade do nutriente em nenhum dos tratamentos. As doses de B aplicadas no solo provocaram acréscimo linear no teor foliar, independentemente da fonte utilizada (Figura 2), ficando os valores $0,2 \mathrm{mg} \mathrm{kg}^{-1}$ (testemunha) e $0,6 \mathrm{mg} \mathrm{kg}^{-1}$ (16 kg ha-1 de B ), dentro das classes sugeridas por Alvarez Venegas et al. (1999), como baixo e médio.

Verificou-se o efeito das diferentes fontes e doses de B sobre os teores foliares dos demais nutrientes (Tabela 2).

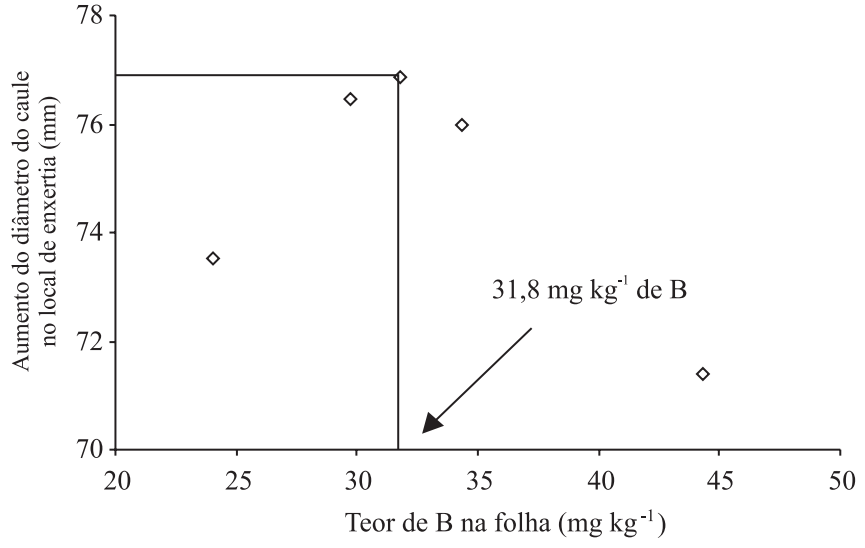

Figura 3. Estimativa do nível crítico de B na folha, através do aumento do diâmetro do caule das mudas de seringueira, utilizando como fonte o ácido bórico.

Tabela 2. Teores de N, P, K, Ca, Mg, S, Na, Cu, Fe, Mn e Zn em folhas de mudas de seringueira, em função de duas fontes de B aplicadas em diferentes doses.

\begin{tabular}{|c|c|c|c|c|c|c|c|c|}
\hline \multirow[t]{2}{*}{ Fontes } & \multicolumn{5}{|c|}{ Doses de B $\left(\mathrm{kg} \mathrm{ha}^{-1}\right)$} & \multirow[t]{2}{*}{ Média } & \multirow{2}{*}{$\begin{array}{l}\text { Efeito } \\
\text { linear }\end{array}$} & \multirow[t]{2}{*}{ Efeito quadrático } \\
\hline & 0 & 2 & 4 & 8 & 16 & & & \\
\hline & \multicolumn{8}{|c|}{$\mathrm{N}\left(\mathrm{g} \mathrm{kg}^{-1}\right)-\mathrm{CV}(\%)=5,79$} \\
\hline Ulexita & 24,2 & 27,0 & 27,2 & 27,3 & 27,8 & 26,7 & ns & ns \\
\hline \multirow[t]{2}{*}{ Ácido bórico } & 24,2 & 26,3 & 26,4 & 26,8 & 27,7 & 26,3 & ns & ns \\
\hline & \multicolumn{8}{|c|}{$\mathrm{P}\left(\mathrm{g} \mathrm{kg}^{-1}\right)-\mathrm{CV}(\%)=8,76$} \\
\hline Ulexita & 1,6 & 1,7 & 1,6 & 1,6 & 1,7 & 1,6 & ns & ns \\
\hline \multirow[t]{2}{*}{ Ácido bórico } & 1,6 & 1,7 & 1,5 & 1,6 & 1,7 & 1,6 & ns & ns \\
\hline & \multicolumn{8}{|c|}{$\mathrm{K}\left(\mathrm{g} \mathrm{kg}^{-1}\right)-\mathrm{CV}(\%)=11,61$} \\
\hline Ulexita & 13,9 & 14,2 & 13,2 & 13,9 & 14,1 & 13,9 & ns & ns \\
\hline \multirow[t]{2}{*}{ Ácido bórico } & 13,9 & 14,3 & 12,6 & 13,3 & 13,6 & 13,5 & ns & ns \\
\hline & \multicolumn{8}{|c|}{$\mathrm{Ca}\left(\mathrm{g} \mathrm{kg}^{-1}\right)-\mathrm{CV}(\%)=11,06$} \\
\hline Ulexita & 6,6 & 6,8 & 6,7 & 6,6 & 6,6 & 6,7 & ns & ns \\
\hline \multirow[t]{2}{*}{ Ácido bórico } & 6,6 & 5,9 & 6,6 & 6,5 & 6,6 & 6,4 & ns & ns \\
\hline & \multicolumn{8}{|c|}{$\mathrm{Mg}\left(\mathrm{g} \mathrm{kg}^{-1}\right)-\mathrm{CV}(\%)=9,49$} \\
\hline Ulexita & 1,6 & 1,5 & 1,7 & 1,6 & 1,6 & 1,6 & ns & ns \\
\hline \multirow[t]{2}{*}{ Ácido bórico } & 1,6 & 1,7 & 1,7 & 1,6 & 1,7 & 1,7 & ns & ns \\
\hline & \multicolumn{8}{|c|}{$\mathrm{S}\left(\mathrm{g} \mathrm{kg}^{-1}\right)-\mathrm{CV}(\%)=19,31$} \\
\hline Ulexita & 2,3 & 2,0 & 2,2 & 2,5 & 2,3 & 2,3 & ns & ns \\
\hline \multirow[t]{2}{*}{ Ácido bórico } & 2,3 & 2,1 & 2,2 & 2,3 & 2,5 & 2,3 & ns & ns \\
\hline & \multicolumn{8}{|c|}{$\mathrm{Na}\left(\mathrm{g} \mathrm{kg}^{-1}\right)-\mathrm{CV}(\%)=16,62$} \\
\hline Ulexita & 1,7 & 1,5 & 1,4 & 1,5 & 1,7 & 1,6 & ns & ns \\
\hline \multirow[t]{2}{*}{ Ácido bórico } & 1,7 & 1,6 & 1,6 & 1,7 & 1,7 & 1,7 & ns & ns \\
\hline & \multicolumn{8}{|c|}{$\mathrm{Cu}\left(\mathrm{mg} \mathrm{kg}^{-1}\right)-\mathrm{CV}(\%)=70,99$} \\
\hline Ulexita & 20,5 & $14,6 \mathrm{a}$ & $9,8 b$ & 16,8 & $11,0 \mathrm{~b}$ & 14,5 & ns & ns \\
\hline \multirow[t]{2}{*}{ Ácido bórico } & 20,5 & $11,0 \mathrm{~b}$ & $24,5 \mathrm{a}$ & 14,0 & $18,5 \mathrm{a}$ & 17,7 & ns & ns \\
\hline & \multicolumn{8}{|c|}{$\mathrm{Fe}\left(\mathrm{mg} \mathrm{kg}{ }^{-1}\right)-\mathrm{CV}(\%)=39,17$} \\
\hline Ulexita & 102,3 & $82,0 \mathrm{~b}$ & 106,5 & 80,0 & 110,7 & 96,3 & ns & ns \\
\hline \multirow[t]{2}{*}{ Ácido bórico } & 102,3 & $134,0 \mathrm{a}$ & 111,0 & 88,8 & 100,8 & 107,4 & ns & ns \\
\hline & \multicolumn{8}{|c|}{$\operatorname{Mn}\left(\mathrm{mg} \mathrm{kg}^{-1}\right)-\mathrm{CV}(\%)=17,35$} \\
\hline Ulexita & 201,0 & 211,5 & 231,5 & 232,3 & 229,3 & 221,1 & $*$ & $* *$ \\
\hline \multirow[t]{2}{*}{ Ácido bórico } & 201,0 & 193,0 & 216,5 & 240,0 & 225,8 & 215,3 & * & * \\
\hline & \multicolumn{8}{|c|}{$\mathrm{Zn}\left(\mathrm{mg} \mathrm{kg}^{-1}\right)-\mathrm{CV}(\%)=17,44$} \\
\hline Ulexita & 30,5 & 32,0 & 38,3 & 36,0 & 35,5 & 34,5 & * & * \\
\hline Ácido bórico & 30,5 & 37,3 & 37,8 & 35,0 & 32,6 & 34,6 & * & * \\
\hline
\end{tabular}

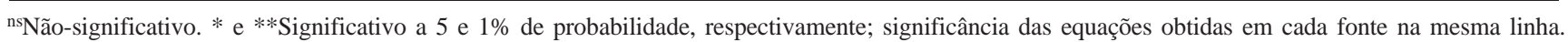


Exceto quanto ao Na, cuja tolerância ou toxidez na seringueira ainda não foi definida, os teores foliares de N, P, K, Ca, Mg, S, Na, Cu, Fe, Mn e Zn, obtidos com as duas fontes de $\mathrm{B}$, ficaram próximos ou dentro das faixas consideradas adequadas por Malavolta et al. (1997), para plantas adultas, e por Viégas et al. (1992), em mudas cultivadas em viveiro com 120 a 180 dias de idade.

Dos elementos analisados, mesmo tendo a ulexita $\mathrm{Ca}$ e $\mathrm{Na}$ na sua constituição $\left(\mathrm{NaCaB}_{5} \mathrm{O}_{6}(\mathrm{OH})\right)$, somente os teores de $\mathrm{Fe}$ e $\mathrm{Cu}$ apresentaram diferenças estatísticas entre as fontes, dentro de cada dose aplicada (Tabela 2). Como o solo apresenta alto teor de Fe, a provável causa desse resultado é a contaminação das folhas durante a coleta, visto que, na dose $2 \mathrm{~kg} \mathrm{ha}^{-1}$ de $\mathrm{B}$, houve efeito significativo sobre o teor foliar de $\mathrm{Fe}$ (Tabela 2). Para o $\mathrm{Cu}$, pode ter havido desuniformidade na aplicação semanal de oxicloreto de cobre a $1,5 \mathrm{~g} \mathrm{~L}^{-1}$ no controle do Thanatephorus curcumeris (Frank.) Donk., o que foi demonstrado pelas diferenças estatísticas aleatórias ocorridas apenas nas doses 2, 4 e $16 \mathrm{~kg} \mathrm{ha}^{-1}$ de $\mathrm{B}$.

Apenas os teores foliares de $\mathrm{Mn}$ e $\mathrm{Zn}$ foram afetados pelas doses de $\mathrm{B}$, com efeito quadrático significativo, independentmente da fonte utilizada (Tabela 2). A ausência de correlação, principalmente com o Ca (Tabela 3), contraria a expectativa inicial, já que o B e o Ca estão associados na formação da parede celular (Epstein \& Bloom, 2005) e apresentam processos semelhantes no movimento da solução do solo para o sistema radicular; a maior presença de um pode induzir a deficiência do outro (Gupta, 1993).
Também não houve correlações significativas entre o B disponível no solo e o teor total na folha com os teores foliares de $\mathrm{P}, \mathrm{K}$ e $\mathrm{S}$, descritas por Loué (1993), e de Mg e Na, por Gupta (1993) (Tabelas 2 e 3). Segundo Furlani et al. (2001), a hipótese para que essas interações não tenham ocorrido se deve aos mecanismos específicos de absorção e transporte que regulam o movimento do $B$ nas plantas serem diferentes daqueles que regulam o movimento dos referidos nutrientes. Independentemente dos tratamentos, houve correla-ções significativas e positivas na planta entre $\mathrm{K}$ e $\mathrm{Na}$, Mg e S e S e Cu e negativas entre $\mathrm{Cu}$ e Mg e Mn e Zn (Tabela 3).

Apesar de ser atribuído papel de inibidor não competitivo ao B, na absorção de Zn (Malavolta et al., 1997), neste trabalho observou-se que a adição de $\mathrm{B}$ no solo, na forma de ácido bórico e ulexita, aumentou o teor foliar de Zn. Esse efeito foi mais evidente na dose $4 \mathrm{~kg} \mathrm{ha}^{-1}$ de $\mathrm{B}$ com aumento de 25,6 e 23,9\% nas duas fontes, respectivamente, quando comparado com a testemunha (Tabela 2); o mesmo foi verificado com os teores foliares, com correlação significativa e positiva (Tabela 3). Segundo Lima Filho \& Malavolta (1998), o B apresenta similaridade com o Zn na absorção e transporte a longa distância pelas plantas, sendo o fluxo de massa e a difusão os principais responsáveis pelo fornecimento desses dois nutrientes da solução do solo para as raízes (Malavolta et al., 1997), estando esses processos diretamente relacionados ao aumento do volume radicular, favorecendo absorção dos nutrientes.

Tabela 3. Coeficientes de correlação entre os teores foliares de mudas de seringueira com todos os resultados de análise obtidos com ácido bórico e ulexita.

\begin{tabular}{|c|c|c|c|c|c|c|c|c|c|c|c|c|}
\hline Nutrientes & $\mathrm{N}$ & $\mathrm{P}$ & $\mathrm{K}$ & $\mathrm{Ca}$ & $\mathrm{Mg}$ & $\mathrm{S}$ & $\mathrm{Na}$ & B & $\mathrm{Cu}$ & $\mathrm{Fe}$ & $\mathrm{Mn}$ & $\mathrm{Zn}$ \\
\hline $\mathrm{N}$ & - & & & & & & & & & & & \\
\hline $\mathrm{P}$ & $0,25_{\mathrm{ns}}$ & - & & & & & & & & & & \\
\hline $\mathrm{K}$ & $0,25_{\mathrm{ns}}$ & $0,52 \mathrm{~ns}$ & - & & & & & & & & & \\
\hline $\mathrm{Ca}$ & $0,13_{\mathrm{ns}}$ & $-0,19_{\mathrm{ns}}$ & $0,02 \mathrm{~ns}$ & - & & & & & & & & \\
\hline $\mathrm{Mg}$ & $0,26_{\mathrm{ns}}$ & $-0,38_{\mathrm{ns}}$ & $0,34_{\mathrm{ns}}$ & $0,27_{\mathrm{ns}}$ & - & & & & & & & \\
\hline $\mathrm{S}$ & $0,68 *$ & $0,10_{\mathrm{ns}}$ & $0,50_{\mathrm{ns}}$ & $0,06_{\mathrm{ns}}$ & $0,58^{*}$ & - & & & & & & \\
\hline $\mathrm{Na}$ & $0,17_{\mathrm{ns}}$ & $0,46_{\mathrm{ns}}$ & $0,72 * *$ & $-0,22_{\mathrm{ns}}$ & $-0,39_{\mathrm{ns}}$ & $0,35_{\mathrm{ns}}$ & - & & & & & \\
\hline B & $0,18_{\mathrm{ns}}$ & $0,05_{\mathrm{ns}}$ & $0,18_{\mathrm{ns}}$ & $0,02 \mathrm{~ns}$ & $0,03_{\mathrm{ns}}$ & $0,31_{\mathrm{ns}}$ & $0,13_{\mathrm{ns}}$ & - & & & & \\
\hline $\mathrm{Fe}$ & $0,23 \mathrm{~ns}$ & 0,23 ns & $0,31_{\mathrm{ns}}$ & $-0,09_{\mathrm{ns}}$ & $-0,19_{\mathrm{ns}}$ & $0,12_{\text {ns }}$ & $0,31_{\mathrm{ns}}$ & $0,13_{\mathrm{ns}}$ & $-0,16_{\mathrm{ns}}$ & - & & \\
\hline Mn & $0,25_{\mathrm{ns}}$ & $0,14_{\mathrm{ns}}$ & $0,25 \mathrm{~ns}$ & $-0,44_{n s}$ & $-0,17_{\mathrm{ns}}$ & 0,32 ns & $0,12_{\mathrm{ns}}$ & $0,40_{\mathrm{ns}}$ & $-0,26_{\mathrm{ns}}$ & $-0,38_{\mathrm{ns}}$ & - & \\
\hline$\underline{\mathrm{Zn}}$ & $0,17_{\mathrm{ns}}$ & $0,05_{\mathrm{ns}}$ & $0,05_{\mathrm{ns}}$ & $-0,06_{\mathrm{ns}}$ & $-0,19_{\mathrm{ns}}$ & $0,27 \mathrm{~ns}$ & 0,09 ns & $0,59 *$ & $-0,06_{\mathrm{ns}}$ & $-0,07_{\mathrm{ns}}$ & $-0,54 *$ & - \\
\hline
\end{tabular}

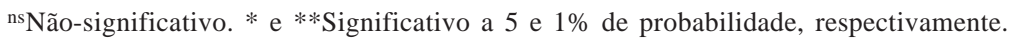




\section{Conclusões}

1. Nas condições edafoclimáticas locais, a seringueira apresenta baixa sensibilidade a fitotoxidez por boro.

2. Em solos com altos teores de argila, Fe e Al, a adubação com ulexita é mais eficiente do que com ácido bórico na obtenção de aumento do diâmetro do caule e do número de raízes laterais.

3. Altas doses de boro não afetam o número de raízes dos porta-enxertos de seringueira.

\section{Referências}

ABREU, M.F.; ABREU, C.A.; ANDRADE, J.C. Determinação de boro em água quente usando aquecimento com microondas. In: RAIJ, B. van; ANDRADE, J.C.; CANTARELLA, H.; QUAGGIO, J.A. (Ed.). Análise química para avaliação da fertilidade de solos tropicais. Campinas: Instituto Agronômico, 2001. p.231-239.

ALVAREZ VENEGAS, V.H.; NOVAIS, R.F.; BARROS, N.F.; CATARUTTI, R.B.; LOPES, A.S. Interpretação dos resultados das análises de solos. In: RIBEIRO, A.C.; GUIMARÃES, P.T.G.; ALVAREZ VENEGAS, V.H. (Ed.). Recomendação para o uso de corretivos e fertilizantes em Minas Gerais, $5^{\mathrm{a}}$ aproximação. Viçosa: SFSEMG, 1999. p.25-32.

BLEVINS, D.G. Future developments in plant nutrition research. In: BOERSMA, L.L. (Ed.). Future developments in soil science research. Madison: Soil Science Society of America, 1987. p.445-458.

BOLLE-JONES, E.W. Nutrition of Hevea Brasiliensis. II. Effect of nutrient deficiencies on growth, chlorophyll, rubber and mineral contents of Tjirandji seedlings. Journal of the Rubber Research Institute of Malaya, v.14, p.209-230, 1954.

EMBRAPA. Centro Nacional de Pesquisa de Solos (Rio de Janeiro, RJ). Manual de métodos de análise de solo. Rio de Janeiro, 1997. 212p.

EPSTEIN, E.; BLOOM, A.J. Mineral nutrition of plants: principles and perspectives. Sunderland: Sinauer Associates, 2005. 400p.

FURLANI, A.M.C.; TANAKA, R.T.; TARALLO, M.; VERDIAL, M.F.; MASCARENHAS, H.A.A. Exigência a boro em cultivares de soja. Revista Brasileira de Ciência do Solo, v.25, p.929-937, 2001.

GUPTA, U.C. Boron and its role in crop production. Boca Raton: CRC Press, 1993. 237p.

HU, H.; BROWN, P.H. Absorption of boron by plant roots. In: DELL, B.; BROWN, P.H.; BELL, R.W. (Ed.). Boron in soils and plants: reviews. Dordrecht: Kluwer Academic Publishers, 1997. p.49-58.

LENOBLE, M.E.; BLEVINS, D.G.; MILES, R.J. Prevention of aluminium toxicity with supplemental boron. II. Stimulation of root growth in an acidic, high-aluminium subsoil. Plant, Cell and Environment, v.19, p.1143-1148, 1996.

LIMA FILHO, O.F.; MALAVOLTA, E. Evaluation of extraction procedures on determination of critical soil and foliar levels of boron and zinc in coffee plants. Communications in Soil Science and Plant Analysis, v.29, p.825-833, 1998.
LOUÉ, A. Oligoéléments en agricultures. Antibes: SCPA-Nathan, 1993. 577p.

MAGALHÃES, J.R.; MONNERAT, P.H. Aplicação foliar de boro na prevenção de deficiência e na composição mineral do tomateiro. Pesquisa Agropecuária Brasileira, v.13, p.81-89, 1978.

MALAVOLTA, E.; VITTI, G.C.; OLIVEIRA, S.A. Avaliação do estado nutricional das plantas: princípios e aplicações. Piracicaba: Potafos, 1997. 319p.

MARSCHNER, H. Mineral nutrition of higher plants. London: Academic Press, 1995. 889p.

MARTENS, D.C.; WESTERMANN, D.T. Fertilizer applications for correcting micronutrient deficiencies. In: MORTVEDT, J.J.; COX, F.R.; SHUMAN, L.M.; WELCH, R.M.(Ed.). Micronutrients in agriculture. Madison: Soil Science Society of America, 1991. p.549-592.

MORAES, L.A.C.; MORAES, V.H.F.; MOREIRA, A. Relação entre flexibilidade do caule de seringueira e a carência de boro. Pesquisa Agropecuária Brasileira, v.37, p.1431-1436, 2002.

NASCIMENTO FILHO, F.J.; ANDO, A.; CRUZ, C.D.; GARCIA, T.B. Análise de caminhamento em mudas de guaraná. Pesquisa Agropecuária Brasileira, v.28, p.447-452, 1993.

PEREIRA, A.V.; PEREIRA, E.B.C. Mudas de seringueira. Manaus: Embrapa-CNPSD, 1986. 52p. (Circular técnica, 29).

PERUZZO, G.; SIQUEIRA, O.J.F.; WIETHÖLTER, S. Eficiência agronômica de fertilizantes nitrogenados para a cultura do trigo. Pesquisa Agropecuária Brasileira, v.29, p.1027-1034, 1994.

PIMENTEL-GOMES, F.; GARCIA, C.H. Estatística aplicada a experimentos agronômicos e florestais. Piracicaba: Fealq, 2002. 309p.

POWER, P.P.; WOODS, W.G. The chemistry of boron and its speciation in plants. In: DELL, B.; BROWN, P.H.; BELL, R.W. (Ed.). Boron in soils and plants: reviews. Dordrecht: Kluwer Academic Publishers, 1997. p.1-14.

RÖMHELD, V. Aspectos fisiológicos dos sintomas de deficiência e toxicidade de micronutrientes e elementos tóxicos em plantas superiores. In: FERREIRA, M.E.; CRUZ, M.C.P.; RAIJ, B. van; ABREU, C.A. (Ed.). Micronutrientes e elementos tóxicos na agricultura. Jaboticabal: CNPq/Fapesp/Potafos, 2001. p.71-88.

SHORROCKS, V.M. Leaf analysis as guide to the nutrition of Hevea brasiliensis. I. Sampling technique with mature trees: principles and preliminary observations on the variations in leaf nutrient composition with position on the tree. Journal of the Rubber Research Institute of Malaya, v.17, p.1-18, 1961.

VIÉGAS, I.J.M.; HAAG H.P.; BUENO, N.; PEREIRA, J.P. Nutrição mineral de seringueira. XII. Absorção de macronutrientes e micronutrientes nos primeiros 240 dias. Scientia Agricola, v.49, p.4152, 1992.

VIEIRA, L.S.; SANTOS, P.C.T.C. Amazônia: seus solos e outros recursos naturais. São Paulo: Ceres, 1987. 416p.

ZHONGGEN, F. Trace elements in soils of rubber growing areas in China. I. Boron. Chinese Journal of Tropical Crops, v.2, p.57-69, 1981. 